\title{
Autoritarismo e adesão a sistemas de valores psicossociais
}

\author{
Thaís Santiago Barros' - Universidade de Brasília, Brasília, Brasil \\ Ana Raquel Rosas Torres²- Universidade Católica de Goiás, Goiânia, Brasil \\ Cícero Pereira - Universidade Católica de Goiás, Goiânia, Brasil
}

\begin{abstract}
Resumo
O objetivo deste trabalho foi investigar as relações entre o autoritarismo e a adesão a sistemas de valores. Para tanto, utilizou-se a escala de Autoritarismo de Extrema-Direita (Altemeyer, 1981, 1988) e o Questionário de Valores Psicossociais (Pereira, Da Costa \& Camino, 2005b). Com base em dados de 284 estudantes universitários de Goiânia, verificou-se que a Escala de Autoritarismo mede duas dimensões políticas: autoritarismo e tolerância. Verificou-se também que os valores religiosos estão relacionados com diminuição da tolerância, enquanto a adesão aos valores hedonistas está relacionada com o aumento da tolerância e com a diminuição do autoritarismo. Além disso, a adesão aos valores materialistas está relacionada com o aumento do autoritarismo. Esses resultados são discutidos ressaltando a importância de uma perspectiva psicossocial que leve em conta os valores contextuais como fatores importantes para a compreensão do apoio das pessoas ao autoritarismo e à democracia.
\end{abstract}

Palavras-chave: autoritarismo; valores psicossociais; perspectiva psicossocial.

Authoritarianism and adhesion to psychosocial values systems

\begin{abstract}
The aim of this study was to investigate the relationships between authoritarianism and the adhesion to values systems. Due to that, Altemeyer's $(1981 ; 1988)$ Right-wing Authoritarianism Scale and the Psychosocial Value Questionnaire (Pereira, Da Costa \& Camino, 2005b) were used. The participants were 284 university students from Goiânia. The results showed that the Authoritarianism Scale was organized in two factors, named authoritarianism and tolerance. The results showed that religious values are negatively correlated to tolerance while hedonist values are positively correlated to this factor. The authoritarianism factor is negatively correlated to hedonist values and positively to materialist values. These results are discussed emphasizing the importance of adopting a psychosocial perspective, taking into account the broader context, in order to analyze political constructs as authoritarianism and democracy.

Keywords: authoritarianism; psychosocial values; psychosocial perspective.
\end{abstract}

\section{Introdução}

A partir da ascensão de regimes totalitários no início do século $\mathrm{XX}$, como o nazismo, o fascismo e o comunismo, o mundo acadêmico começou a se interessar profundamente pelo conceito de autoritarismo e suas relações com fenômenos tais como etnocentrismo e preconceito, bem como com o apoio de indivíduos às ideologias autoritárias (Stellmacher \& Petzel, 2005). No entanto, nos últimos anos, voltamos a ver o crescimento do apoio a regimes totalitários, principalmente no oriente médio. Contudo, embora revestido de nuances mais brandas, esse fenômeno também pode ser visto nas democracias ocidentais como, por exemplo, os ataques xenofóbicos recentes ocorridos na Europa. Esses fatos em conjunto mostram que os estudos sobre o autoritarismo voltam a ter uma relevância não

\footnotetext{
1 Pesquisa realizada com apoio do CNPq por meio de bolsa de mestrado para a primeira autora.

2 Endereço para correspondência: Av. Portugal, 41, apt. 903, Setor Oeste, Goiânia -GO, 74140-020. E-mail: arr.torres@gmail.com
}

apenas acadêmica, mas também social, pois, como apontam as manchetes de jornais de todo o mundo, nenhuma nação está livre de se ver tomada por um regime autoritário.

Por outro lado, a retomada dos estudos sobre o autoritarismo traz consigo uma novidade na forma como esse construto tem sido analisado. De uma perspectiva explicativa fortemente psicológica, como o trabalho original de Adorno, Frenkel-Brunswik, Levinson e Sanford (1950), passou-se gradativamente para estudos mais psicossociais. Nesses estudos, o autoritarismo é visto não como uma característica de personalidade individual, mas como algo que muda de acordo com certos contextos políticos e que é mediado por fatores tais como a identidade social (Stellmacher \& Petzel, 2005) e os valores (Feldman, 1993). Outro importante fator para a análise do autoritarismo é a adesão a sistemas de valores, pois, como afirmou Rokeach (1968), eles são centrais na organização das atitudes e são a base para a construção e manutenção de sistemas políticos (Cochrane, Billig \& Hogg, 1979; Lipset, 1982; Pereira, Torres \& Barros, 2004; Rokeach, 
1979; Tetlock, 1986). No presente artigo, investiga-se a relação entre o autoritarismo e a adesão a sistemas de valores.

\section{Autoritarismo: antigas e novas perspectivas teóricas}

De acordo com Brown (1996, p. 76), o autoritarismo pode ser definido como

an orientation which is overly differential to those in authority whilst simultaneously adopting an overbearing and hostile attitude towards those perceived as inferior. It is also commonly associated with a very conventional value system in which "right" and "wrong" are unambiguously demarcated and deviant or minority groups are openly derogated.

O estudo de Adorno e cols. (1950) sobre a personalidade autoritária é considerado a origem das investigações sistemáticas sobre esse tema. O objetivo desses autores era compreender o fenômeno do preconceito e da intolerância racial a partir de um ponto de vista psicanalítico. O principal pressuposto teórico desse trabalho é o fato que, para os autores, o desenvolvimento da personalidade em ambientes repressivos, rígidos e severos em relação à disciplina levariam o indivíduo, já na infância, ao deslocamento dos impulsos agressivos contra os pais para outros alvos. Geralmente, esses outros alvos seriam pessoas pertencentes aos grupos minoritários percebidos como mais fracos ou inferiores.

Para Adorno e cols. (1950), os indivíduos que são socializados numa sociedade sob um regime político autoritário tendem a se submeter às autoridades e a se posicionar no lado político dominante. Esses indivíduos nutrem uma confiança excessiva nas autoridades e tornam-se mais predispostos ao autoritarismo por acreditarem que compartilham o poder e a fama daqueles que apoiam. Por outro lado, a internalização dessas normas exerceria a função de proteção nos momentos em que as figuras de autoridade não estiverem presentes, minimizando a ansiedade. E mais, qualquer crítica feita a essas normas é vista pelo indivíduo como um ataque à sua própria pessoa. De uma maneira bem sucinta, os indivíduos autoritários teriam como características principais a intolerância com membros de outros grupos (os exogrupos), principalmente se esse grupo for uma minoria social (judeus, homossexuais, negros etc.). Uma segunda característica importante seria o apego às tradições e a inflexibilidade em aceitar mudanças. $\mathrm{Ou}$ seja, seriam pessoas fundamentalistas e dogmáticas.
A explicação da teoria da personalidade autoritária (Adorno \& cols., 1950) para as reações autoritárias é de que elas são consequências do não-desenvolvimento de mecanismos e estratégias independentes para lidar com situações de crise, o que sobrecarrega o estado emocional e cognitivo do indivíduo, levando-o a agir de maneira hostil. Com relação a esse tipo de ação, Oesterreich (2005) afirma que existem duas situações em que os indivíduos com personalidade autoritária agem com agressividade: quando seus superiores os mandam agir agressivamente e quando seus superiores não podem ajudá-los em situações de crise porque também estão sendo atacados. No entanto, apesar do enorme sucesso e longevidade dessa teoria, ela também tem sofrido severas críticas.

O primeiro grupo de críticas refere-se ao caráter reducionista da teoria da personalidade autoritária, pois por meio dela buscava-se explicar atitudes preconceituosas quanto a fatores de personalidade. Logo, ao analisar o preconceito (o que necessariamente exige investigações num nível intragrupal e intergrupal de análise) sob a ótica da personalidade individual, que se localiza no nível intrapessoal de análise, negligenciou-se os contextos históricos, situacionais e socioculturais envolvidos nas ideologias preconceituosas, muitas vezes correlacionadas com o autoritarismo (Duckitt, 1989; Monteiro, 1993; Stellmacher \& Petzel, 2005). Por outro lado, os críticos também apontam outro tipo de reducionismo nessa teoria. Os autores reduziram os participantes a apenas dois tipos: autoritários e não-autoritários, e, a partir daí, fizeram uma descrição detalhada das respectivas características de personalidade. Mas, segundo Martin (2001), quais seriam as características do indivíduo mediano, que eram a maioria dos estudos de Adorno e cols. (1950). Essa questão continua em aberto até os dias de hoje.

O segundo grupo de críticas refere-se aos aspectos metodológicos, pois, de acordo com Oesterreich (2005), um problema central para os estudos empíricos é o de que as escalas que buscam medir o conceito de personalidade autoritária são, na verdade, escalas que medem atitudes políticas, desviando-se assim de seu principal objetivo. Por outro lado, especificamente no que se refere à escala $F$ (de fascismo) de Adorno e colaboradores (1950), o grande problema psicométrico refere-se ao fato de que todos os itens estavam na mesma direção, ou seja, maior valor, fascismo mais forte, o que, segundo 
Smith (1997), poderia ter inflacionado as correlações entre os itens, uma vez que a psicologia da concordância é diferente da psicologia da discordância.

No terceiro grupo de críticas, questiona-se, atualmente, que as medidas de autoritarismo levam em conta apenas as orientações políticas de extrema-direita e negligenciam a possibilidade da existência de autoritarismo de ideologia de extrema-esquerda (Stone \& Smith, 1993). Segundo Stellmacher e Petzel (2005), essa questão ainda está sem respostas nas pesquisas sobre autoritarismo.

$\mathrm{Na}$ atualidade, um dos principais autores que continuam estudando o autoritarismo é Altemeyer (1996). Esse autor primeiro se afastou da visão psicanalítica de Adorno e cols. (1950) e, em seguida, aproximou-se do conceito de autoritarismo da Teoria da Aprendizagem Social de Albert Bandura (1986). Altemeyer defende que o autoritarismo se desenvolve no processo de aprendizagem social por meio da observação, modelagem e reforçamento. Nesse caso, a adolescência foi apontada por ele como um dos períodos mais importantes no processo de desenvolvimento de crenças e atitudes sobre autoridade e convenções sociais (Smith \& Winter, 2002).

Altemeyer (1981, 1988, 1996) desenvolveu a Teoria do Autoritarismo de Extrema-Direita (Theory of Right-Wing Autoritarianism - RWA) e definiu o autoritarismo como sendo a combinação de três grupos de atitudes: a) Submissão autoritária - que consiste no alto grau de submissão às autoridades de determinada sociedade; b) Agressão autoritária - que consiste num tipo de agressividade geral, dirigida a várias pessoas, percebida como legitimada pelas autoridades; c) Conservadorismo - que consiste numa adesão elevada às convenções e às tradições sociais estabelecidas e endossadas pela sociedade e pelas autoridades. Para medir o autoritarismo com base nessa definição, o autor desenvolveu uma escala de autoritarismo (Right-Wing Autoritarianism - RWA), que tem sido muito utilizada em vários estudos sobre autoritarismo por suas qualidades psicométricas (Feldman, 2003; Peterson, Duncan, \& Pang, 2002).

Os estudos de Altemeyer são considerados de extrema relevância no desenvolvimento da psicologia política (Smith, 1997). Entre seus estudos encontram-se aqueles em que ele demonstrou que as pessoas que apresentam elevados escores na escala de autoritarismo não percebem a rigidez de seus sistemas de crenças. Ele demonstrou também, mediante estudos experimentais, que os participantes autoritários apresentam duplos padrões rígidos e impermeáveis acerca da justiça social, doutrinação religiosa e direitos do Estado direcionados para grupos minoritários, mas não para os grupos majoritários (Peterson, Duncan, \& Pang, 2002). Em outras palavras, para as pessoas com alta adesão ao autoritarismo, a rigidez da lei e da ordem seria maior para as minorias do que para as maiorias sociais.

Mais recentemente, um novo olhar sobre a questão do autoritarismo foi apresentado por Feldman (2003), que sugeriu que qualquer teoria sobre o autoritarismo deve levar em conta

the conflict between a social order based on social conformity and the desire to maximize personal autonomy. The way in which people deal with this conflict leads to the relative preference they place on the values of social conformity and personal autonomy. It is this value dimension, I argue, that is the basis of the authoritarianism phenomenon (Feldman, 2003, p. 66).

Para Feldman (2003) as pessoas que valorizam a conformidade têm também uma visão muito pessimista da natureza humana, que traz em sua essência a idéia de que os indivíduos precisam de normas rígidas para conviver em sociedade, caso contrário, cairiam na barbárie. Eles também defendem punições rígidas para aqueles que se desviaram das normas sociais, sendo inclusive a favor de limitar a liberdade e os direitos civis. Por outro lado, para esse autor, aquelas pessoas que valorizam a autonomia pessoal mais do que a conformidade social também acreditam na habilidade das pessoas de interagir em liberdade e com autonomia e ainda assim viverem uma estabilidade social.

Para demonstrar suas hipóteses, Feldman (2003) realizou uma pesquisa em que procurava evidenciar que a existência de uma relação entre a dimensão conformidade-autonomia e a percepção de ameaça contribuem para o preconceito racial e a intolerância, e também examinar a relação entre a dimensão conformidade-autonomia, ideologia e autoritarismo de extrema-direita. Este estudo, feito com 266 estudantes universitários, demonstrou que aqueles participantes que valorizam a conformidade social e que perceberam o outro grupo como ameaçador da coesão social são também os mais preconceituosos e intolerantes e 
que apresentam também os mais altos escores na escala de autoritarismo (RWA).

Após a breve revisão sobre as principais teorias do autoritarismo, passaremos a discutir as abordagens teóricas mais importantes na literatura em psicologia social sobre os valores sociais, para posteriormente apresentar os principais estudos que relacionam esses dois construtos.

\section{Sistemas de valores e autoritarismo}

O grande interesse na Psicologia Social pelo estudo dos valores deve-se ao reconhecimento de que eles atuam como padrões que guiam condutas tanto individuais quanto grupais, fornecem soluções para conflitos, orientam na manutenção da ordem social e produzem modelos para avaliações e julgamentos sociais (Rokeach, 1973). Desse modo, muitos estudiosos produziram modelos teóricos que contribuíram para a explicitação dos valores como um construto social.

$\mathrm{Na}$ teoria da estrutura dos valores individuais (Schwartz \& Bilsky, 1987; 1990)

Valores (a) são conceitos on crenças, (b) pertencem a estados finais desejáveis on comportamentos, (c) transcendem situações específicas, (d) guiam a seleção ou a avaliação de comportamentos e eventos, e (e) são ordenados em função de sua importância (Schwartz \& Bilsky, 1990, p.878).

Nessa teoria, os conteúdos dos valores são chamados tipos motivacionais, pois expressam tipos universais de interesses ou necessidades que motivam as pessoas. Eles se organizam numa estrutura de duas dimensões de ordem superior a partir das similaridades e diferenças entre esses tipos motivacionais. As dimensões individuais de valores que se encontram em oposição autotranscedência versus autopromoção e abertura à mudança versus conservação - são consideradas incompatíveis entre si. Os valores que são próximos, formadores de cada uma das dimensões, são considerados compatíveis entre si. Entretanto, o valor hedonismo integra tanto a dimensão abertura à mudança quanto a dimensão autopromoção.

Numa perspectiva sociológica, Inglehart (1990, 1991, 1994) investigou a influência das mudanças sociopolítico-econômicas nos valores, principalmente os políticos, nas sociedades industrializadas. Com base em dados coletados em países dos cinco continentes durante várias décadas, esse autor formulou a teoria dos valores materialistas e pós-materialistas. Esses valores organizam-se num continuum onde, de um lado, situam-se os membros das sociedades que optam pelos valores materialistas como metas importantes a serem atingidas pelo país, do outro lado, estão os membros da sociedade que escolhem os valores pós-materialistas como metas importantes a serem atingidas pelo país. No meio termo estariam aqueles membros da sociedade que optam conjuntamente por valores materialistas e pós-materialistas. $O$ postulado principal desse autor defende que valores materialistas e pósmaterialistas são conjuntos distintos de valores e, necessariamente, opostos. No entanto, essas idéias têm sido intensamente revisadas por investigadores que têm utilizado diversos métodos de análise, especialmente aqueles que trabalham numa abordagem psicossociológica.

No Brasil, tem sido desenvolvida uma abordagem psicossociológica (Pereira, Da Costa \& Camino, 2005a; 2005b; Pereira, Lima \& Camino, 2001) que propõe articular teorias psicológicas sobre os valores, tais como as de Rokeach (1968) e Schwartz (1992), com a teoria sociológica desenvolvida por Inglehart (1990; 1991). Essa abordagem se baseia no pressuposto de que a fonte dos valores está nas identidades ideológicas que orientam os interesses dos grupos e não nas necessidades individuais, como foi sugerido nas abordagens psicológicas do estudo dos valores (para uma revisão, ver Da Costa, 2000). Nesse sentido, os valores são concebidos como conhecimentos socialmente estruturados a partir dos diversos conteúdos ideológicos contidos no interior de uma sociedade (Pereira, Da Costa \& Camino, 2005b).

Nessa perspectiva, os valores psicossociais se agrupam em quatro sistemas, quais sejam: hedonista (prazer, uma vida excitante, sexualidade e sensualidade); religioso (obediência às leis de Deus, religiosidade, salvação da alma e temor a Deus); materialista (riqueza, autoridade, status e lucro) e pós-materialista, composto pelos subsistemas de bem-estar social (justiça social, liberdade, igualdade e fraternidade); bem-estar individual (alegria, amor, conforto e autorrealização) e bem-estar profissional (realização profissional, dedicação ao trabalho, responsabilidade e competência).

Mas qual a relação entre adesão a sistemas de valores e posicionamentos político-ideológicos? Feather (1993) constatou que os estudantes australianos que votavam em partidos liberais de extrema-direita eram mais autoritários do que os estudantes que votavam na extrema-esquerda 
trabalhista. Torres (1992) verificou que a adesão de estudantes universitários ao sistema de valores autoritários correlacionava-se negativamente com a aceitação do socialismo e com a identificação com partidos de esquerda. Posteriormente, Lima (1997) investigou os valores e as atitudes face à democracia e ao autoritarismo numa amostra de estudantes de universidades privada e pública de João Pessoa. Quanto à amostra da universidade privada, verificou-se que a atitude positiva com relação à democracia era mais frequente entre os estudantes do sexo masculino, que menos aderiam ao sistema de valores religioso-hieráquicos e mais ao sistema do bem-estar. Nessa mesma universidade, os estudantes mais autoritários aderiam aos sistemas de valores econômico e religioso-hierárquico. Também os estudantes da universidade privada demonstraram ser mais autoritários do que os da universidade pública. $\mathrm{Na}$ amostra da universidade pública, Lima (1997) observou que a aceitação do autoritarismo por esses estudantes vinha acompanhada de menor idade, maior adesão ao sistema de valores econômicos, baixa disposição ao voto e pouca participação em organizações políticas.

Barnea e Schwartz (1998) investigaram as dimensões de valores responsáveis pelo voto de cidadãos israelenses por meio da teoria dos tipos motivacionais. Os resultados demonstraram que as escolhas políticas daqueles estudantes eram influenciadas por dois tipos de ideologia: uma democrática, fundamentada nas características do liberalismo clássico; e uma autoritária, fundamentada na manutenção da ordem social e dos valores religiosos. Ainda, a adesão aos valores de autotranscendência influenciava positivamente a preferência por partidos de ideologia democrática e negativamente a preferência por partidos de ideologia religiosa. Já a adesão aos valores de conservação se relacionou negativamente com a preferência por partidos democráticos, e positivamente à escolha por partidos religiosos.

Objetivando analisar as bases motivacionais que estão relacionadas com o autoritarismo de direita (Altemeyer, 1981, 1988, 1996) e com a orientação à dominância (Pratto, Sidanius, Stallworth \& Malle, 1994), Cohrs, Moschner, Maes e Kielmann (2001) realizaram uma pesquisa com participantes alemães logo depois dos atentados ao World Trade Center. Utilizando o modelo dos valores humanos de Schwartz (1992), esses autores demonstraram que esses dois construtos, embora próximos em termos conceituais, têm bases motivacionais parcialmente diferentes. Assim, os resultados de uma análise fatorial realizada por esses autores mostraram que o conservadorismo está mais próximo do autoritarismo de direita do que da orientação à dominância. Por outro lado, ambos os construtos se encontram em oposição à autotranscedência e à autopromoção.

Tendo como objetivo validar o Questionário de Valores Austríacos, Renner, Salem e Alexandrowicz (2004) analisaram a relação entre autoritarismo e adesão ao nacionalismo, religiosidade fundamentalista e abertura a mudança. Os resultados por eles encontrados mostraram a existência de correlações positivas entre $\mathrm{O}$ autoritarismo, a religiosidade fundamentalista e o nacionalismo e uma correlação negativa entre autoritarismo e abertura a mudança.

Tomados em conjunto, os trabalhos que investigaram as relações entre autoritarismo e adesão a sistemas de valores apontam que, de diferentes formas, esse construto se relaciona com valores ligados à tradição e ao conservadorismo. Assim, seguindo a mesma linha de raciocínio, este trabalho tem como objetivo específico demonstrar a validade do modelo psicossocial de valores para analisar as ancoragens sociais do autoritarismo. Assim, espera-se que os níveis mais altos de autoritarismo se correlacionem positivamente com os valores religiosos e materialistas e negativamente com os valores hedonistas e pósmaterialistas.

\section{Método}

\section{Participantes}

Duzentos e oitenta e quatro (284) estudantes universitários de uma universidade privada da cidade de Goiânia (Goiás) participaram deste estudo. A idade média desses estudantes era 24 anos, com desvio padrão de 6,46. Oitenta por cento dos participantes eram do sexo feminino e $20 \%$ do sexo masculino.

\section{Instrumento}

Para medir os valores aplicou-se o Questionário de Valores Psicossociais (QVP-24) (Pereira, Da Costa \& Camino, 2005b). Os participantes eram instruídos a atribuírem uma nota de zero a dez aos valores que julgavam importantes para a construção de uma sociedade ideal para se viver. Os seguintes valores eram apresentados: alegria, amor, autorrealização, 
competência, conforto, dedicação ao trabalho, fraternidade, igualdade, justiça social, liberdade, realização profissional, responsabilidade, autoridade, status, riqueza, uma vida excitante, lucro, sexualidade, obediência às leis de Deus, religiosidade, salvação da alma, temor a Deus, sensualidade, prazer.

Após o questionário de valores, aplicou-se a Escala de Autoritarismo de Altemeyer (1988; 1996), traduzida e adaptada pelo Grupo de Pesquisa sobre os Processos Grupais da UCG. Esta escala possui 30 itens em formato likert, indo de 1 (discordo totalmente) a 7 (concordo totalmente). Essa escala visa medir três principais tipos de atitudes (Altemeyer, 1981; Knight, 1999): submissão autoritária, agressão autoritária e conservadorismo. Nesse trabalho, escores altos representam uma atitude mais favorável ao autoritarismo. Como exemplo dos itens dessa escala, temos: a) Não há nada realmente errado com muita coisa que algumas pessoas chamam de pecados; b) Todos deveriam ter seu próprio estilo de vida, crenças religiosas e preferência sexual, até mesmo se isso faz com que ele seja diferente dos outros.

\section{Procedimentos}

O questionário foi respondido individualmente, porém sua aplicação foi coletiva em sala de aula, após a autorização do professor responsável pela turma. O tempo de aplicação variou de 20 a 30 minutos.

\section{Resultados}

O Questionário de Valores Psicossociais (QVP-24) foi analisado por meio de duas técnicas de análise multivariada - análise de agrupamento (Hierarchical Cluster Analysis - HCA) e escalonamento multidimensional (Multidimensional Scaling - MDS). Ambas as técnicas possuem objetivos semelhantes: observar as distâncias euclidianas entre as variáveis para a construção de grupos (clusters) dessas variáveis (Aldenderfer \& Blashfild, 1984) e identificar as dimensões psicológicas responsáveis pela organização dos grupos de variáveis. O grau de ajustamento das variáveis às dimensões obtidas é medido pelo estresse (Abelson, 1967). A medida do estresse deve apresentar coeficiente inferior a 0,15 para que as dimensões sejam adequadas para a interpretação dos resultados (Kruskal \& Wish, 1978). A Figura 1 apresenta os resultados obtidos na HCA e na MDS. Como podemos verificar, a importância atribuída pelos estudantes aos valores do QVP24 - pode ser agrupada em quatro grupos de valores que se organizaram em duas dimensões (estresse $=0,07$ e $R^{2}=0,98$ ). A primeira dimensão contrapõe o grupo de valores materialistas (riqueza, lucro, status, autoridade) ao grupo de valores pós-materialistas (competência, realização profissional, dedicação ao trabalho, igualdade, justiça social, alegria, autorrealização, fraternidade, responsabilidade, amor, liberdade, conforto). A segunda dimensão contrapõe o grupo de valores religiosos (obediência a Deus, religiosidade, salvação da alma, temor a Deus) ao grupo de valores hedonistas (sexualidade, prazer, sensualidade e uma vida excitante). Apenas os sistemas materialistas e hedonistas são correlacionados moderadamente $(r=0,56)$. As demais correlações são fracas, pois seus valores estão entre $r=0,26$ e $r=0,17$. Ressalte-se que, seguindo Schwartz (1992) as semelhanças entre as médias dos 24 itens utilizados foram controladas subtraindo-as dos valores das escalas de cada sistema.

A Escala de Autoritarismo (Altemeyer, 1988; 1996) foi submetida à análise dos componentes principais (PCA). A medida de adequabilidade da amostra, obtida pelo teste Kaiser-Meyer-Olkin (KMO), é 0,75. Diferente dos resultados encontrados por Altemeyer (1981), nos quais um fator foi suficiente para reunir itens sobre a submissão à autoridade, a agressão autoritária e o conservadorismo, neste estudo dois fatores emergiram na análise dos componentes principais, ambos com autovalores maiores que 1,00. Esses dois fatores são completamente independentes, pois a correlação entre eles é não significativa $(r=0,06$, n.s.). Além disso, dos trinta itens propostos na escala, quatro foram excluídos por terem apresentado cargas fatoriais menores do que 0,30. A interpretação dos fatores indica que o primeiro pode ser denominado "tolerância" porque reuniu itens ligados às atitudes voltadas para a aceitação das diferenças de crenças, de práticas sexuais e religiosas e a proteção dos direitos humanos. Esse fator explicou $16 \%$ da variância, com elevada consistência interna (alfa de Cronbach=0,83). O segundo fator, denominado "autoritarismo", aglutinou itens referentes ao que Altemeyer (1981) chamou de submissão à autoridade e agressão autoritária. Esse fator explicou $13 \%$ da variância e obteve boa consistência interna (alfa de Cronbach $=0,77$ ). Procedeu-se também à análise dessa escala fixando-se o número de fatores em apenas um fator, mas houve uma redução considerável na 
variância explicada, passando de $29 \%$ para $16,5 \%$. solução de dois fatores.

Assim, diante desses resultados, optou-se pela

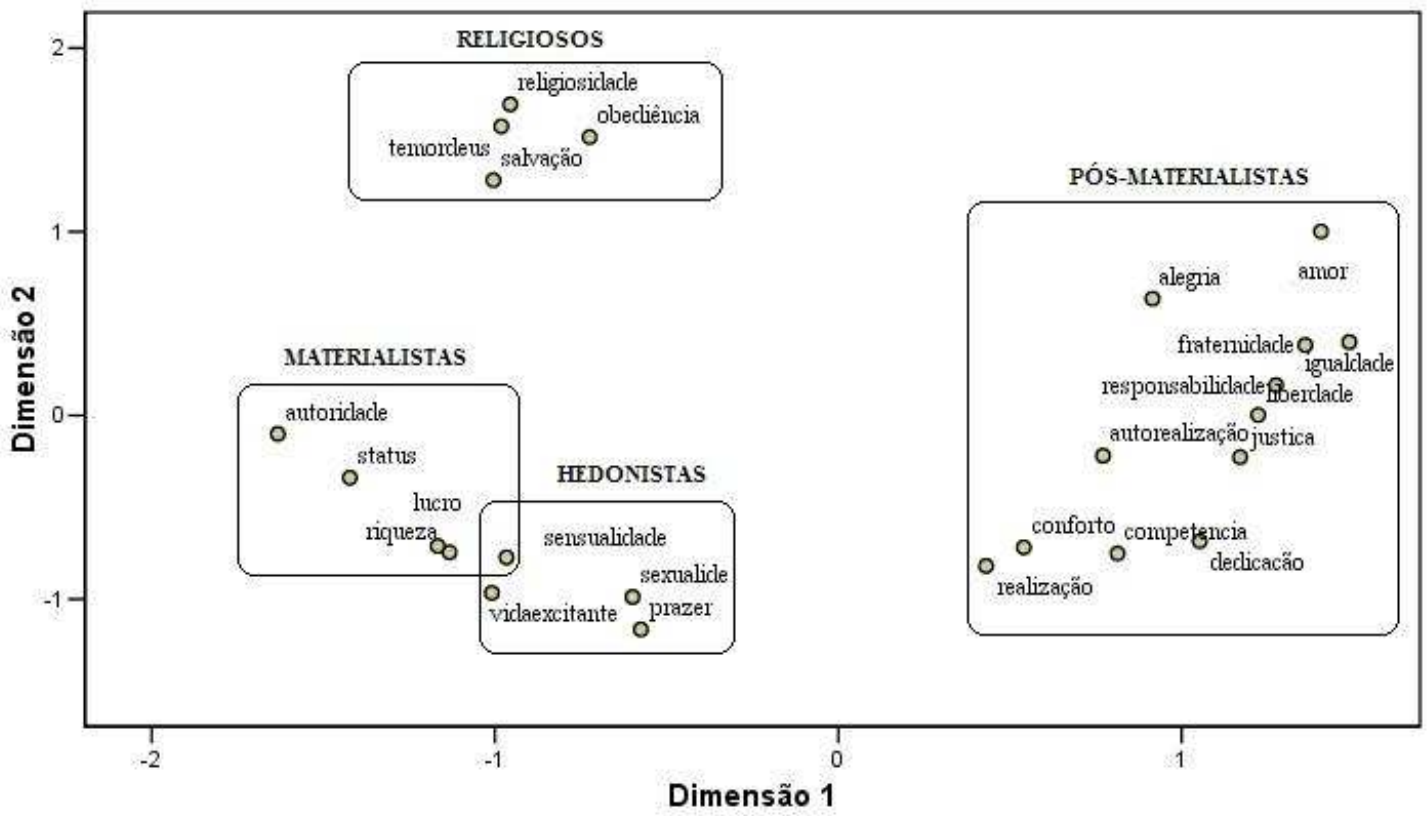

Figura 1. Configuração dos sistemas de valores dos estudantes universitários

A Tabela 1 apresenta os resultados de dois modelos de regressão múltipla ${ }^{3}$ nos quais foram estimados os efeitos dos quatro sistemas de valores na tolerância e no autoritarismo. Como se pode verificar, o modelo para a tolerância mostra um coeficiente de regressão múltipla substancial e significativo: $R=0,44, F(2,226)=6,95 ; p<0,001$. A análise dos parâmetros estimados indica que uma relação negativa e significativa entre a adesão aos valores religiosos e a "tolerância" $(\beta=-0,41 ; t=$ $6,90 ; p<0,001)$ e uma relação positiva e significativa entre os valores hedonistas e essa "tolerância" $(\beta=0,27 ; \quad t=4,45 ; \quad p<0,001)$. Neste sentido, os estudantes menos tolerantes são aqueles com maior adesão aos valores religiosos (obediência a Deus, religiosidade, salvação da

\footnotetext{
${ }^{3}$ Seguimos as recomendações propostas por Tabchinick e Fidell (2001) concernentes aos modelos de regressão múltiplas. No presente estudo, a inspeção dos valores de skewness e kurtosis das medidas indica que apenas os valores pós-materialistas apresentam distorção na sua distribuição em relação à curva normal. De maior importância, a análise dos resíduos indica que estes são homogêneos e são normalmente distribuídos, tal como mostraram os testes de Kolmogorov-Smirnov para a normalidade dos resíduos: $Z_{\text {Tolerância }}=0,85, \quad n s$. $Z_{\text {Autoritarismo }}=0,90, n s$. Finalmente, os dados não contêm casos extremos (outliers) univariados ou multivariados, nem existe multicolinearidade entre os preditores (tolerâncias $>0,80$ ).
}

alma, temor a Deus), enquanto os estudantes mais tolerantes são aqueles com maior adesão aos valores do hedonismo (sexualidade, prazer, sensualidade).

No que se refere ao autoritarismo, o coeficiente de regressão também é significativo: $R=0,22, F(2,246)=6,55 ; p<0,001$. A análise dos parâmetros estimados indica uma relação positiva e significativa entre os valores materialistas e o autoritarismo $(\beta=0,27 ; t=3,60 ; \mathrm{p}<0,00)$ e uma relação negativa e significativa entre os valores hedonistas e o autoritarismo $(\beta=-0,18 ; t=2,34$; $p<0,02)$. Isto significa que os estudantes com maior tendência ao autoritarismo são aqueles com maior adesão ao materialismo (riqueza, lucro, vida excitante, status, autoridade), enquanto que os menos autoritários são aqueles com maior adesão aos valores hedonistas (sexualidade, prazer, sensualidade).

\section{Discussão}

Neste trabalho foram analisadas as relações entre o autoritarismo e a adesão a sistemas de valores. Primeiramente, a escala de autoritarismo (Altemeyer, 1988, 1996) não resultou em um único fator. Este resultado não corrobora pesquisas realizadas noutros países por Cohrs e colaboradores (2001), Duckitt (1989), Feldman (2003) e de Stellmacher e Petzel (2005). No 
entanto, ele está em consonância com a perspectiva psicossocial que defende que construtos políticos (autoritarismo e democracia) devem ser estudados dentro de contextos específicos e não como estruturas de personalidade fixas e imutáveis. Os resultados aqui verificados mostram a existência de dois fatores autoritarismo e tolerância - que são completamente independentes entre si (isto é, não são correlacionados) e, mais importante, eles se relacionam de forma muito diferente com os sistemas de valores aqui utilizados. $\mathrm{O}$ autoritarismo se relaciona positivamente com o sistema de valores materialistas e negativamente com os valores hedonistas. Já a tolerância se relaciona negativamente com os valores da religiosidade e positivamente com os valores hedonistas. No entanto, acreditamos que futuros estudos devem aprofundar a análise da estrutura do autoritarismo bem como a relação entre esse construto e outros semelhantes, como por exemplo, a orientação à dominância tal como fizeram Cohrs e colaboradores (2001).

Tabela 1. Regressões múltiplas, pelo método stepwise, tendo o autoritarismo e a tolerância como variáveiscritério e os sistemas de valores psicossociais com variáveis independentes.

\begin{tabular}{|c|c|c|c|c|}
\hline & & \multicolumn{3}{|c|}{ Variável-critério: Tolerância } \\
\hline Preditores & Médias (desvio padrão) & Beta & $\mathrm{t}$ & $\mathrm{p}<$ \\
\hline Materialismo & $6,17(2,31)$ & $-0,02$ & $-0,23$ & n.s. \\
\hline Pós-materialismo & $9,47(0,84)$ & 0,07 & 1,20 & n.s. \\
\hline Religioso & $7,72(2,62)$ & $-0,41$ & $-6,90$ & 0,00 \\
\hline Hedonismo & $7,43(2,05)$ & 0,27 & 4,45 & 0,00 \\
\hline Variância explicada & & \multicolumn{3}{|c|}{$R^{2}=0,20 ; R^{2}$ Ajustado $=0,19$} \\
\hline Significância do modelo & & \multicolumn{3}{|c|}{$F(2,234)=28,70 ; p<0,001$} \\
\hline & & \multicolumn{3}{|c|}{ Variável-critério: Autoritarismo } \\
\hline Preditores & Médias (desvio padrão) & Beta & $\mathrm{t}$ & $\mathrm{p}<$ \\
\hline Materialismo & $6,17(2,31)$ & 0,27 & 3,60 & 0,00 \\
\hline Pós-materialismo & $9,47(0,84)$ & 0,07 & 1,02 & n.s. \\
\hline Religioso & $7,72(2,62)$ & 0,11 & 1,75 & n.s. \\
\hline Hedonismo & $7,43(2,05)$ & $-0,18$ & $-2,34$ & 0,02 \\
\hline Variância explicada & & \multicolumn{3}{|c|}{$R^{2}=0,05 ; R_{\text {Ajustado }}^{2}=0,04$} \\
\hline Significância do modelo & & \multicolumn{3}{|c|}{$F(2,246)=6,55 ; p<0,001$} \\
\hline
\end{tabular}

O fato de os fatores do autoritarismo serem ortogonais (não correlacionados) sugere que as pessoas podem, simultaneamente, serem tolerantes e autoritárias, ou não serem autoritárias, mas não serem tolerantes. De fato, essa possibilidade é coerente com resultados encontrados por Coelho (2000) onde, embora os participantes prefiram a democracia como forma de governo, eles poderiam, dependendo da situação, aceitar um líder autoritário. Em outras palavras, a aceitação do autoritarismo ou da democracia como possíveis formas de governo para o Brasil pode variar de acordo com o contexto político apresentado.

No que se refere aos valores que são importantes para uma sociedade ideal, constatouse que a forma como os universitários de Goiânia organizam os seus sistemas valorativos é semelhante à verificada outros estudos (Pereira, Da Costa \& Camino, 2005a, 2005b; Pereira, Lima
\& Camino, 2001). O fato a ser destacado é que os quatro sistemas de valores podem não apresentar relações de conflito entre si como salientado noutras abordagens (por exemplo, Schwartz, 1992), mas podem influenciar diferentemente as atitudes políticas. Realmente, os resultados mostraram que os valores religiosos estão na base das atitudes menos tolerantes, os valores materialistas fundamentam as atitudes autoritárias, enquanto os valores hedonistas contribuem para o aumento da tolerância e para a diminuição do autoritarismo. Portanto, como previsto, os valores psicossociais estão na base do desenvolvimento das atitudes autoritárias dos estudantes universitários.

\section{Referências}

Abelson, R. P. (1967). A technique and a model of multi-dimensional attitude scaling. Em M. 
Fishbein (org.), Readings in attitude: Theory and measurement (pp. 349-356). Nova Iorque: John Wiley e Sons.

Adorno, T. W., Frenkel-Brunswik, E., Levinson, D. J. \& Sanford, R. N. (1950). The authoritarian personality. Nova Iorque: Harper \& Row.

Aldenderfer, M. S. \& Blashfield, R. K. (1984). Cluster Analysis. Beverly Hills: Sage.

Altemeyer, B. (1981). Right-wing authoritarianism. Manitoba: University Press.

Altemeyer, B. (1988). Enemies of freedom. São Francisco: Jossey-Bass.

Altemeyer, B. (1996). The authoritarian specter. Cambridge, MA: Harvard University.

Bandura, A. (1986). Social foundations of thought and action: a social cognitive theory. Englewood Cliffs, NJ: Prentice Hall.

Barnea, M. F. \& Schwartz, S. H. (1998). Values and voting. Political Psychology, 19, 17-40.

Brown, R. (1996). Authoritarianism. Em A. S. R. Manstead \& M. Hewstone. The Blackwell Encyclopedia of Social Psychology. Oxford: Blackwell

Cochrane, R., Billig, M., \& Hogg, M. (1979). British politics and the two-value model. In M. Rokeach (org.), Understanding human values: Individual and societal (pp. 179-191). Nova Iorque: Free.

Coelho, M. F. P. (2000). O gosto pela política. Em C. E. P. Araújo, E. G. C. Santos, J. Souza, \& M. F. P. Coelho (orgs.). Política e Valores, (pp. 6177). Brasília, DF: Editora Universidade de Brasília.

Da Costa, J. B. (2000). Visões sociais de democracia: Um estudo psicossociológico dos significados da democracia. Tese de Doutorado. São Paulo: Pontifícia Universidade Católica de São Paulo, SP.

Deschamps, J. C. \& Devos, T. (1993). Valeurs, cultures et changement. Intercultures, 1, 17-28.

Duckitt, J. (1989). Authoritarianism and group identification: a new view of and old construct. Political Psychology, 10, 63-84.

Feather, N. T. (1993). Authoritarian and attitudes toward high achievers. Journal of Personality and Social Psychology, 65, 152-164.
Feldman, S. (2003). Enforcing social conformity: a theory of authoritarianism. Political Psychology, 24 (1), 41-73.

Inglehart, R. (1990). Culture shift in advanced industrial society. Princeton, NJ: Princeton University Press.

Inglehart, R. (1991). El cambio cultural en las sociedades industriales avanzadas. Madri: Siglo XXI.

Inglehart, R. (1994). Modernización y postmodernización: la cambiante relación entre el desarrollo económico, cambio cultural y político. Em J. D. Nicolas, \& R. Inglehart (orgs.), Tendências mundiales de cambio em los valores sociales y políticos (pp.157-170). Madri: Fundesco.

Knight, K. (1999). Liberalism and conservatism. Em J. P. Robinson, P. R. Shaver, \& L. S. Wrightsman, (orgs.). Measures of political attitudes, 2. (59-158). London: Academic Press.

Kruskal, J. B., \& Wish, M. (1978). Multidimensional scaling. London: Sage.

Lima, M. E. (1997). Valores, participação política, atitudes face à democracia e ao autoritarismo: uma análise da socialização política dos universitários da Paraíba. Dissertação de Mestrado. João Pessoa: Universidade Federal da Paraíba.

Lipset, S. M. (1982). The academic mind at the top: the political behavior and values of faculty elites. Public Opinion Quarterly, 46, 143168.

Martin, J. L. (2001). The authoritarian personality, 50 years later: what lessons are there for political psychology? Political Psychology, 22(1), $1-26$.

Monteiro, M. B. (1993). Conflito e cooperação nas relações intergrupais. Em J. Vala \& M. B. Monteiro (Orgs.). Psicologia Social (pp. 287307). Lisboa: Fundação Calouste Gulbenkian.

Oesterreich, D. (2005). Flight into security: a new approach and measure of the authoritarian personality. Political Psychology, 26, 275-297.

Pratto, F., Sidanius, J., Stallworth, L. M. \& Malle, B. F. (1994). Social dominance orientation: a personality variable predicting social and political attitudes. Journal of Personality and Social Psychology, 67 (4), 741-763. 
Pereira, C., Da Costa, J., \& Camino, L. (2005a). Um estudo sobre a articulação dos níveis de análise dos sistemas de valores. Psicologia: Reflexão e Crítica, 18 (1), 16-25.

Pereira, C., Da Costa, J. \& Camino, L. (2005b). Análise fatorial confirmatória do Questionário de Valores Psicossociais - QVP24. Estudos de Psicologia, 9(3), 505-521.

Pereira, C., Lima, M. E. O. \& Camino, L. (2001). Sistemas de valores e atitudes democráticas de estudantes universitários de João Pessoa. Psicologia: Reflexão, Crítica, 14 (1), 177-190.

Pereira, C., Torres, A. R. R. \& Barros, T. S. (2004). Sistemas de valores e atitudes democráticas de estudantes universitários. Psicologia: Teoria e Pesquisa, 20(1), 001-010.

Peterson, B. E., Duncan, L. E., \& Pang, J. S. (2002). Authoritarianism and political impoverishment: deficits in knowledge and civic disinterest. Political Psychology, 23, 97-109.

Renner, W., Salem, I. \& Alexandrowicz, R. (2004). Human values as predictors for political, religious and health-related attitudes: a contribution towards validating the Austrian Value Questionnaire (AVQ) by structural equation modeling. Social Behavior and Personality, 32 (5), 477-490.

Rokeach, M. (1968). Beliefs, attitudes and values. São Francisco: Jossi-bass.

Rokeach, M. (1973). The nature of buman values. Nova Iorque: Free Press.

Rokeach, M. (1979) Introduction. Em M. Rokeach (Org.). Understanding human values: Individual and societal (pp. 1-11). New York: Free Press.

Schwartz, S. H. (1992). Universals in the content and structure of values: theoretical advanced and empirical tests in 20 countries. Em M. Zanna (org.), Advances in experimental social psychology, 25 (pp. 01-65). Orlando: Academic Press.
Schwartz, S. H. \& Bilsky, W. (1987). Toward a universal psychological structure of human values. Journal of Personality and Social Psychology, 53, 550-562.

Schwartz, S. H., \& Bilsky, W. (1990). Toward a Theory of the Universal Content and Structure of Values Extensions and CrossCultural Replications. Journal of Personality and Social Psychology, 58, 878-891.

Smith, A. G., \& Winter, D. G. (2002). Right-wing authoritarianism, party identification, and attitudes toward feminism in student evaluations of the Clinton-Lewinsky story. Political Psychology, 23, 355-383.

Smith, M. B. (1997). The authoritarian personality: A re-review 46 years later. Political Psychology, 18, 159-163.

Stellmacher, J. \& Petzel, T. (2005). Authoritarianism as a group phenomenon. Political Psychology, 26, 245-273.

Stone, W. F., \& Smith, L. D. (1993). Authoritarianism: Left and right. Em W. F. Stone, G. Lederer, and R. Christie (Orgs.). Strength and weakness. The authoritarian personality today (pp. 144-156). New York: Springer.

Tabachnick, B. G. \& Fidel, L.S. (2001). Using multivariate statistics. Boston: Allyn and Bacon.

Tetlock, P. E. (1986). A value pluralism model of ideological reasoning. Journal of Personality and Social Psychology, 50, 819-827.

Torres, A. R. R. (1992). Uma análise psicossocial da identificação partidária: $O$ caso dos estudantes da UFPb nas eleicôes de 1988, 1989 e 1990. Dissertação de Mestrado. João Pessoa: Universidade Federal da Paraíba.

Recebido em julho de 2007 Reformulado em maio de 2008 Aprovado em agosto de 2008 
Sobre os autores:

Thaís Santiago Barros é psicóloga e mestre em Psicologia pela Universidade Católica de Goiás, e doutoranda no Programa de Doutorado em Psicologia Social, do Trabalho e Organizacional da Universidade de Brasília, professora da Faculdade Projeção (Brasília). Tem experiência na área de Psicologia, com ênfase em Psicologia Social, trabalhando com atribuições de causalidade, sistemas de valores e comportamento político.

Ana Raquel Rosas Torres é psicóloga, mestre em Psicologia pela Universidade Federal da Paraíba. Realizou o doutorado em Psicologia pela University of Kent em Canterbury (Reino Unido) e o pósdoutorado em Psicologia Social pela Université de Pronvence (França). É professora titular de psicologia da Universidade Católica de Goiás. Atualmente estuda os sentimentos intergrupais relacionados ao preconceito e discriminação.

Cícero Pereira é psicólogo e mestre em Psicologia Social pela Universidade Federal da Paraíba. Realizou o doutorado em Psicologia Social no Instituto Superior de Ciências do Trabalho e da Empresa e o pósdoutorado no Instituto de Ciências Sociais da Universidade de Lisboa. Desde 2001 é professor de Psicologia Social na Universidade Católica de Goiás. Atualmente estuda os mecanismos de legitimação do preconceito e da discriminação. 